Service social

\title{
Le contrat en travail social, sous la direction de Christina De Robertis, Paris, Collection Travail social, Bayard Éditions, 1993.
}

\section{Hélène Boulet}

Volume 43, numéro 3, 1994

Intervention individualisée et empowerment

URI : https://id.erudit.org/iderudit/706675ar

DOI : https://doi.org/10.7202/706675ar

Aller au sommaire du numéro

Éditeur(s)

École de service social de l'Université Laval

ISSN

1708-1734 (numérique)

Découvrir la revue

Citer ce compte rendu

Boulet, H. (1994). Compte rendu de [Le contrat en travail social, sous la direction de Christina De Robertis, Paris, Collection Travail social, Bayard

Éditions, 1993.] Service social, 43(3), 156-157. https://doi.org/10.7202/706675ar d'utilisation que vous pouvez consulter en ligne.

https://apropos.erudit.org/fr/usagers/politique-dutilisation/ 


\section{LE CONTRAT EN TRAVAIL SOCIAL}

Sous la direction de Cristina De Robertis

Paris, Collection Travail social, Bayard Éditions, 1993.

Ce livre regroupe des textes de différents auteurs sous la direction de Cristina De Robertis. Il se présente comme une systématisation des connaissances sur le contrat en intervention sociale, tel qu'il est conçu, régi et pratiqué en France.

Dans un premier chapitre, après avoir cerné le concept de contrat, les auteurs s'adressent aux lecteurs friands d'une perspective historique. Ils jettent un regard sur les conceptions du contrat présentées dans les textes bibliques, sur les apports fournis par les sociétés romaines, féodales et par la Renaissance. Ils abordent ensuite l'évolution apportée à cette notion par le philosophe Jean-Jacques Rousseau et les innovations venant des approches juridique et linguistique.

Les deuxième et troisième chapitres sont plus universels. Cristina De Robertis y spécifie les contributions de l'approche résolution de problème, des approches à court terme, de l'intervention en situation de crise et de I'analyse systémique dans I'utilisation des contrats en service social. Elle précise ensuite l'importance de la méthodologie dans la construction du contrat, sa mise en œuvre et elle souligne certaines difficultés systémiques rencontrées au moment de l'application des contrats. Elle nous fait réfléchir aux notions d'éthique à la base de toute intervention de type contractuel dont l'autonomie et l'autodétermination, l'acceptation et le respect, la confiance et la discrétion, la mobilisation et le partage. Globalement, elle présente une approche qui fait confiance aux capacités des clients et qui leur donne un rôle actif tout au long du processus. Finalement, elle souligne la réalité de certaines contradictions dans la pratique du contrat, contradictions qui en dénaturent le sens.

Dans le quatrième chapitre, I'auteur élabore une typologie des contrats dans les politiques sociales françaises où l'action sociale a un rôle à jouer. Chacun de ces types de contrat est analysé à partir de quatre grandes variables: les règles déterminantes des contrats, leurs modes d'élaboration, leurs effets et les rapports de pouvoir inhérents à toute relation sociale. Ici, il ouvre sur une certaine perspective critique.

Le cinquième chapitre montre les assises de l'utilisation du contrat en intervention sociale collective. L'auteur définit l'apparition de nouvelles politiques sociales en action collective et il amorce une réflexion qui est à poursuivre sur leurs implications dans une pratique collective de type contractuel.

Le chapitre suivant regroupe des extraits de textes de lois, de décrets et de formulaires qui régissent le contexte des services de l'aide sociale à l'enfance. Ces écrits traduisent la volonté du législateur de faire participer les usagers aux démarches d'information de décision et de 
planification de l'action. Le lecteur québécois pourrait ici faire un parallèle avec des extraits de la Loi sur la protection de la jeunesse, des recommandations du rapport Harvey, les formulaires reliés aux mesures volontaires et les ententes prises lors des placements d'enfants.

Le septième chapitre illustre, à partir de trois situations de la pratique en protection de l'enfance, une démarche de résolution de problème de type contractuel, c'est-à-dire une démarche où l'intervenant part des problèmes ressentis par les clients, fixe avec eux des objectifs précis, des étapes et partage ouvertement avec eux les rôles et les responsabilités de chacun.

Le dernier chapitre présente le contrat dans le cadre de la Loi sur le revenu minimum d'insertion. Deux assistantes sociales dépeignent leurs expériences de travail. Une première, qui travaille en polyvalence de secteur, situe les parties concernées par le contrat d'insertion, dépeint le rôle de l'assistante sociale et celui des partenaires, et souligne les implications pour sa pratique de ce type d'intervention. Une deuxième, qui travaille dans un cadre associatif auprès de gens sans domicile fixe, montre la spécificité de son approche auprès de cette population et l'importance des éléments du contexte matériel et social dans l'amorce de sa démarche contractuelle.

Ce livre aborde des thèmes très divers autour de la notion de contrat. En ouvrant sur un tel éventail de thèmes, les auteurs font bien ressortir les notions de base du contrat déjà présentes dans la littérature du service social, mais non toujours organisées d'une façon systématique. Ce livre peut donc servir d'initiation pour des étudiants au contrat. La perspective globale ouvrant de nombreuses pistes d'analyse critique de l'utilisation des contrats en service social, les étudiants pourront s'y référer afin $\mathrm{d}^{\prime}$ amorcer leur réflexion. Pour leur part, les intervenants habitués à utiliser une démarche contractuelle apprécieront la systématisation des connaissances mais ils resteront sur leur appétit quant au raffinement de leur démarche. Précisons finalement que, bien que ce livre soit destiné aux assistantes sociales françaises, les travailleurs sociaux québécois peuvent y faire de nombreux parallèles avec leur pratique et le contexte de cette pratique.

Hélène BOULET

Chargée de cours École de service social, Université Laval 